\author{
Sanneke A. M. van Vliet • Marjan J. Jongsma • \\ Raymond A. P. Vanwersch • Berend Olivier • \\ Ingrid H. C. H. M. Philippens
}

\title{
Behavioral effects of modafinil in marmoset monkeys
}

Received: 6 June 2005 / Accepted: 2 February 2006 / Published online: 21 March 2006

(C) Springer-Verlag 2006

\begin{abstract}
Rationale: Modafinil is increasingly used in sleep disturbances in general and in neurodegenerative diseases and is recently being used in healthy people for attention control. However, the application of modafinil is possibly not only restricted to alertness enhancing effects. More insight in this compound may lead to new applications. Not all behavioral aspects have been studied sufficiently; therefore, more detailed investigations on modafinil's positive and aversive behavioral effects are addressed in this paper. Objectives: Determination of effects of modafinil in marmoset monkeys with observational methods and with behavioral tests measuring locomotor activity, hand-eye coordination, response to a threat situation and startle response. Materials and methods: Two hours after oral administration of modafinil in doses of $50,100,150$, and $225 \mathrm{mg} / \mathrm{kg}$, animals were observed and tested in the behavioral test systems. Results: Locomotor activity was increased after $100 \mathrm{mg} /$ $\mathrm{kg}$ modafinil in the Bungalow test and after 100, 150, and $225 \mathrm{mg} / \mathrm{kg}$, as found in the movement parameters of the human threat test. Moreover, modafinil showed anxiolyticlike effects in the human threat test. No other side effects were observed, nor were the hand-eye coordination and startle response affected. Conclusions: Besides psychostimulation, modafinil has no aversive effects in the doses used in the domains measured. The potential anxiolytic-
\end{abstract}

\footnotetext{
S. A. M. van Vliet $(\bowtie) \cdot$ M. J. Jongsma $\cdot$ R. A. P. Vanwersch I. H. C. H. M. Philippens

Department of Diagnosis and Therapy, TNO Defence,

Security and Safety,

Lange Kleiweg 137,

2288 GJ Rijswijk, The Netherlands

e-mail: vliet_s@pml.tno.nl

Tel.: +31-15-2843246

Fax: $+31-15-2843963$

S. A. M. van Vliet · B. Olivier · I. H. C. H. M. Philippens Department of Psychopharmacology,

Utrecht Institute of Pharmaceutical Sciences,

Utrecht University,

Sorbonnelaan 16 ,

3584 CA Utrecht, The Netherlands

e-mail: philippens@pml.tno.nl
}

like effects of modafinil may create new possibilities for the therapeutic use of modafinil.

Keywords Modafinil - Marmoset monkey $\cdot$ Behavior · Side effects · Activity · Anxiety · Hand-eye coordination . Startle reflex

\section{Introduction}

Modafinil is a vigilance-enhancing compound approved as treatment for excessive daytime sleepiness (EDS) in narcolepsy (Bastuji and Jouvet 1988; Green and Stillman 1998). Modafinil is also effective in many other neurological diseases associated with EDS (Happe 2003; Rammohan et al. 2002) including reduction of fatigue in multiple sclerosis (Rammohan et al. 2002) and Parkinson's disease (Adler et al. 2003; Happe et al. 2001; Nieves and Lang 2002).

Besides effects on alertness, modafinil has other putative therapeutic applications. The sedative effects of antipsychotics and opiates or sedation after general anesthesia can be reduced (Larijani et al. 2004; Makela et al. 2003; Webster et al. 2003). Modafinil also supports and augments the effects of antidepressants (Menza et al. 2000; Ninan et al. 2004). Furthermore, modafinil treatment reduces impulsivity and hyperactivity in ADHD patients (Taylor and Russo 2000; Turner et al. 2004). Positive effects on cognition were also found in healthy humans (Turner et al. 2003).

As an alertness enhancer, modafinil is preferred over amphetamine and amphetamine-like stimulants, because of its lower abuse and dependency potential (Jasinski and Kovacevic-Ristanovic 2000) and a favorable side effect profile. In humans, modafinil is well tolerated with side effects reported as mild to moderate headache, nausea, nervousness, anxiety, and insomnia (Robertson and Hellriegel 2003).

The exact mechanism of action of modafinil is still unclear. The morphological distribution of neural active areas after modafinil implicates involvement in sleep-wake 
regulation, like the anterior hypothalamic nucleus and adjacent areas, but not in motor function areas (Engber et al. 1998; Lin et al. 1996; Scammell et al. 2000). Modafinil modulates neurotransmitter function, such as noradrenaline (NA) indirectly, as modafinil-induced locomotor activity is prevented by an $\alpha_{1}$-adrenoreceptor antagonist (Duteil et al. 1990). It also affects GABA, reducing its release in striatum, sleep-related areas, and the outflow of the cortex (Ferraro et al. 1998; Ferraro et al. 1996; Tanganelli et al. 1995)

The functional effects of modafinil should be more intensively studied because of the increased application of modafinil in therapeutic areas like Parkinson's disease, depression, and sleep, but also its extended therapeutic use and possible attention-enhancing effects in healthy people. To approach the human situation as much as possible, a non-human primate model was selected with a high level of similarity to human sleep architecture: the marmoset monkey. This model also has a high level of similarity to human Parkinson's disease after MPTP intoxication. The marmoset monkey is a good model for testing modafinil because its closer resemblance to man compared to rodent. Whereas, many of the physiological and pharmacological questions can be (and have been) addressed in rodent models and tests, behavioral and cognitive parameters can be assessed more accurately in animals closer to man. Furthermore, in primate models, similar test methods can be used in humans. For example, the abnormal involuntary movement scale (AIMS), a clinical rating scale for dyskinesia, can be applied without modification to PD patients (Di Monte et al. 2000), and sleep EEG measurements also show high similarity (Philippens et al. 2004).

In the present study, the effects of modafinil in doses of $50,100,150$, and $225 \mathrm{mg} / \mathrm{kg}$ were assessed using observation scales and behavioral test systems. Direct observation with extensive observation scales, measuring effects on general and dyskinetic behavior, quantified the effects of modafinil.

The quality of movement was measured with behavioral test systems assessing the locomotor activity, the hand-eye coordination and startle response. Measurement of the effects of modafinil on the hand-eye coordination is unique. Also, little research is done concerning the effects of modafinil on anxiety. Therefore, in this study, the reaction to the human threat has been tested.

\section{Materials and methods}

\section{Animals}

Adult male and female marmoset monkeys (Callithrix jacchus) aged 2-6 years with body weights between 350$550 \mathrm{~g}$ were obtained from BPRC, The Netherlands and Harlan, United Kingdom. Marmosets are social animals, but due to practical purposes, among others, the validation of observational tests in single-housed marmosets, the animals were kept one to a cage. Moreover, the marmosets were supplied as individuals; therefore, it was less stressful for these animals to keep them singly housed. The ambient temperature was regulated at $25 \pm 2^{\circ} \mathrm{C}$ and the relative humidity was always $>60 \%$. A 12 -h light-dark cycle was maintained. All aspects of animal care are described in Standard Operating Procedures, which are in agreement with current guidelines of the European Community. The independent TNO committee on Animal Care and Use approved all protocols for the animal experiments.

\section{Study design}

Modafinil was administrated orally by gavage in doses of $50,100,150$, and $225 \mathrm{mg} / \mathrm{kg}$. The doses chosen were based on earlier studies in marmosets, rats, and mice (Jenner et al. 2000; Engber et al. 1998; Duteil et al. 1990). The peak activity of modafinil in marmoset monkeys was $2 \mathrm{~h}$ after administration with effects lasting more than a 10 -h period (Jenner et al. 2000). Consequently, the appearance of symptoms was observed and the human threat test was carried out at 120 min after administration followed by the hand-eye coordination task at $130 \mathrm{~min}$ post-dose. At $145 \mathrm{~min}$ post-dose, the locomotor activity was assessed in the Bungalow test, followed by the startle response at $170 \mathrm{~min}$ post-dose. To reduce the number of animals, each animal received a maximum of two different doses of modafinil in a randomized design. The number of animals used in the test systems (hand-eye coordination, locomotor activity, and startle response) is five $(50 \mathrm{mg} / \mathrm{kg})$, nine $(100 \mathrm{mg} / \mathrm{kg})$, eight $(150 \mathrm{mg} / \mathrm{kg})$, and six $(225 \mathrm{mg} / \mathrm{kg})$. The startle response is tested in five animals after $225 \mathrm{mg} / \mathrm{kg}$ modafinil due to a technical failure. To extend the reliability of the data, extra observations with the human threat test and the behavior scales of five animals $[50 \mathrm{mg} /$ $\mathrm{kg}(n=1), 100 \mathrm{mg} / \mathrm{kg}(n=4)]$ were added. Control values were obtained in the same animals without treatment. No differences between control and vehicle values were found (data not shown).

\section{Drug administration}

Modafinil (Modiodal, d,1-2-[(diphenylmethyl)sulfinyl] acetamide) was used in ground tablet form (Laboratoire L. Lafon, France). One tablet contains $100 \mathrm{mg}$ modafinil and filling compounds, such as lactose, cornstarch, magnesium monosilicate $2 \mathrm{H}_{2} \mathrm{O}$, sodium croscarmellose, polyvidon, talc, and magnesium stearate. Before usage, the ground tablets were homogenized freshly in a $10 \%$ sugar solution in a dose volume of $1.5 \mathrm{ml} / \mathrm{kg}$. The used doses of modafinil were $50,100,150$, and $225 \mathrm{mg} / \mathrm{kg}$.

\section{Behavioral assessment \\ Observation of signs and symptoms}

For the observation of signs and symptoms, two rating scales were used: 1) a general clinical scoring list in which 
the condition of the animal was rated. The following symptoms were taken into account: inadequacy of grooming by inspection of the fur; apathy by testing the responsiveness of the animal to its surrounding; immobility and presence of tremors. The rates of severity were coded from 0 (normal) to 4 (severe). 2) The abnormal involuntary movement scale (AIMS) is a nine-item rating scale, designed to record in detail the occurrence of dyskinetic movements (Guy 1976). The AIMS is widely used clinically for qualification of dyskinetic movements, occurring among others in Parkinson's disease, schizophrenia, and the elderly (Beasley et al. 1999; Katzenschlager et al. 2004; Woerner et al. 1998). This scale has successfully been applied for more than 10 years in monkey research in our institute. The AIMS includes facial, mouth (lips, peri-oral area, jaw, and tongue), extremity, and trunk movements. The global judgment of the severity and the incapacitation due to the abnormal movements were also scored. All items were rated from 0 (normal) to 4 (severe). Movements that occur upon stimulation by the observer were rated one step lower than those observed spontaneously. The observations were performed in a blinded matter. Besides the rating scales, the deviation from the normal behavior not mentioned in the above-mentioned scales was registered.

\section{Spontaneous exploratory behavior (Bungalow test)}

The levels of activity and exploratory behavior can play an important role in practically all measurements of animal behavior. A device called the 'Bungalow test' can automatically and quantitatively assess these parameters. The test is described and validated by Wolthuis et al. (1994) and Philippens et al. (2000). The apparatus consists of four horizontally placed non-transparent boxes $(23 \times 23 \times 23 \mathrm{~cm})$ all interconnected by six PVC tubes (inner diameter $9.5 \mathrm{~cm}$ ). The animals were placed in the same compartment at the start of each session. The animals could freely move and change from one compartment to another during the 20-min session. A video tracking system (Ethovision, Noldus) registered the locomotor activity of the animal, expressed as the number of compartment changes during the session.

\section{Hand-eye coordination task}

Assessment of the hand-eye coordination can reveal information about vigilance and performance. For this task, an automated robot-guided apparatus with positive reinforcement as a motivating stimulus (small pieces of marshmallow) has been developed. As described and validated by Philippens et al. (2000), the marmoset is placed in front of a test panel provided with a window $(8 \times 5 \mathrm{~cm})$. A robot arm presents a reward behind the window. With this system, three types of trials were performed: one using a non-moving reward in the middle of the window, another using a slow horizontally moving reward $(0.04 \mathrm{~m} / \mathrm{s})$, and still another using a fast horizontally moving reward $(0.08 \mathrm{~m} / \mathrm{s})$. The animal was allowed for $1 \mathrm{~min}$ to grasp the non-moving reward. Each type of trial was performed 14 times in one session. At the beginning of each trial a sound signal was presented, intended to alarm the animal. A pressure detector and infrared detectors in the window were used to register hits and attempts and speed of performance. A 'hit' was registered when the animal successfully retrieved the reward from the robot arm. The percentage of correct hits was used as a criterion to judge the performance of the animal.

\section{Human threat test}

The human threat test is a non-human primate putative model of anxiety. It is based on findings that marmosets will exhibit fear-related behavior in the presence of a human observer in front of the cage (Costall et al. 1988). Most pronounced behavior would be retreating to the back of the cage and showing characteristic postures.

The behavior was assessed in the home cage $(40 \times 60 \times 60 \mathrm{~cm})$ with a hanging basket in the back of the cage, a wooden board $(20 \times 10 \mathrm{~cm}, 30 \mathrm{~cm}$ above the cage floor) on the left side in the back, and on the other side a perch, at the same height, positioned from the back to the front of the cage.

To assess the behavior, the observer stood approximately $30-100 \mathrm{~cm}$ from the cage front and made eye contact with the marmoset throughout a 2-min test period. During this period, the movements, behavior, and position of the marmoset in the cage were recorded by video registration.

A range of parameters were obtained according to Carey et al. (1992) based on Stevenson and Poole (1976): 1) The number of characteristic postures exhibited: tail posture (tail raise to present the genital region), scent marking (the anal and genital area is pressed against the substrate to be marked with excretion of the glands), arched pilo (arched back posture with full body pilo-erection), slit stare (stare with the eyes half-closed in combination with tufts flattened and exposure of the teeth), rearing (upright position with flexed paws), twisting (head and torso movement from side to side), 2) The time spent in the front of the cage, 3) The number of position changes in the cage, 4) The number of movements from the back of the cage to the front, and 5) The number of jumps from the left side of the cage to the right side or vice versa.

\section{Auditory startle response}

The startle response is a sensitive method to determine how different neurotransmitter systems or drugs modulate sensorimotor activities. The startle reflex appears also to be under the control of higher brain centers; for instance, a state of anxiety potentiates the startle response (Koch 1999). The auditory startle reflex is a motor response after an intense sound stimulus. The apparatus for marmoset monkeys has been described earlier and validated by 
Philippens et al. (2000). The animals were placed in a transparent plastic tube on a pressure transducer in an illuminated sound attenuated box. Twenty startle stimuli (20 ms, $120 \mathrm{~dB}$, white noise) were delivered in random order $(14 \pm 4 \mathrm{~s})$. For the duration of $200 \mathrm{~ms}$, the force exerted by the animal upon presentation of the stimulus was registered. The startle reflex was represented by the amplitude.

\section{Statistics}

No statistical analysis was performed on the data of the behavioral observation scales because the changes can be regarded as minimal.

The remaining results are presented as mean \pm SEM and parametric statistical analysis was applied. The study can be considered as a semi-within design, as some animals received multiple doses; however, not all doses. Therefore, the statistical analysis is based on a between-subjects design. First, an overall repeated measures analysis was applied where the dose-group (the animals belonging to a certain dose with a certain treatment) was the betweenfactor and the treatments, control, and modafinil were included as the within-factor. If the $p$ value $<0.05$ or a clear trend was seen, a paired $t$ test was applied to test each dosegroup for a difference between the treatment groups. For this analysis, the significance level of $p<0.05$ was used.

\section{Results}

Observation of signs and symptoms

Administration of $50,100,150$, and $225 \mathrm{mg} / \mathrm{kg}$ modafinil resulted in none or minimal changes in the rating scales (clinical symptoms and AIMS). In Table 1 the mean scores of the affected animals and the number of affected animals are shown. Most changes on both rating scales were within normal ranges (score of 1 means normal behavior with the parameter seen in a higher frequency). Only scores above ' 1 ' are defined as affected behavior. Therefore, only in the lowest dose group $(50 \mathrm{mg} / \mathrm{kg})$ were three parameters rated as affected (Table 2). By observation, an increased activity after high doses of modafinil was seen. After $150 \mathrm{mg} / \mathrm{kg}$, some stability problems were seen. After the highest dose, some animals were hyperactive, showing fast and repetitive-but not stereotypic-movements, increased distraction, and escape attempts.

\section{Quality of movements}

Modafinil affected the locomotor and exploratory activity measured with the Bungalow test $[F(1,24)=12.7, p<0.001]$ and the hand-eye coordination $[(F(1,24)=8.4, p<0.01)]$. More specifically, the locomotor activity after $100 \mathrm{mg} / \mathrm{kg}$ modafinil was increased compared to the normal activity $(p<0.05$, Fig. 1). The difference in number of compartment changes between the control value and $100 \mathrm{mg} / \mathrm{kg}$ modafinil was $115 \pm 46$. The hand-eye coordination task, measured as the number of correctly taken rewards, was still at maximum performance after $50(n=5), 100(n=9)$,

Table 1 Overview of the mean scores of the affected animals on the items of the clinical score (a) and the AIMS (b) after administration of $50(n=6), 100(n=13), 150(n=8)$, and $225 \mathrm{mg} / \mathrm{kg}(n=6)$ modafinil

\begin{tabular}{|c|c|c|c|c|c|}
\hline & & \multicolumn{4}{|c|}{ Modafinil (mg/kg) } \\
\hline & & 50 & 100 & 150 & 225 \\
\hline \multicolumn{6}{|l|}{ a) Clinical score } \\
\hline & Grooming & $1(1 / 6)$ & $1(4 / 13)$ & $1(6 / 8)$ & $1(3 / 6)$ \\
\hline & Apathy & $1(2 / 6)$ & $1(3 / 13)$ & $1(1 / 8)$ & $1(3 / 6)$ \\
\hline & Immobility & $1.5(2 / 6)$ & 0 & 0 & 0 \\
\hline & Tremors & 0 & 0 & 0 & 0 \\
\hline \multicolumn{5}{|l|}{ b) AIMS test } & 5 out of 6 \\
\hline \multirow[t]{4}{*}{ Facial and oral movements } & Facial expression & $2(1 / 6)$ & 0 & 0 & 0 \\
\hline & Lips and perioral area & $1(2 / 6)$ & $1(1 / 13)$ & $1(1 / 8)$ & $1(2 / 6)$ \\
\hline & Jaw & 0 & 0 & $1(2 / 8)$ & 0 \\
\hline & Tongue & 0 & $1(1 / 13)$ & 0 & 0 \\
\hline \multirow[t]{2}{*}{ Extremity movements } & Upper & 0 & $1(1 / 13)$ & 0 & 0 \\
\hline & Lower & $1.5(2 / 6)$ & 0 & 0 & $1(2 / 6)$ \\
\hline Trunk movements & Neck, shoulder, hips & $1(2 / 6)$ & 0 & $1(3 / 8)$ & $1(1 / 6)$ \\
\hline \multirow[t]{2}{*}{ Global judgment } & Severity & 0 & 0 & 0 & 0 \\
\hline & Incapacitation & $1(1 / 6)$ & 0 & 0 & $1(1 / 6)$ \\
\hline Total affected animals & & 5 out of 6 & 3 out of 13 & 5 out of 8 & 6 out of 6 \\
\hline
\end{tabular}

0: normal; 1: minimal, but extreme normal; 2: mild; 3: moderate; 4: severe (affected animals/total group size) 
Table 2 Overview of the difference between the parameters of the human threat test before and after administration of $50(n=6)$, 100 $(n=13), 150(n=8)$, and $225(n=6) \mathrm{mg} / \mathrm{kg}$ modafinil

\begin{tabular}{|c|c|c|c|c|}
\hline & \multicolumn{4}{|c|}{ Modafinil (mg/kg) } \\
\hline & 50 & 100 & 150 & 225 \\
\hline No. of body postures & $-5.2 \pm 1.2 *$ & $-2.8 \pm 1.3$ & $-5.8 \pm 2.3^{*}$ & $-4.8 \pm 1.0 *$ \\
\hline Time spent in front $(\mathrm{sec})$ & $-8.3 \pm 5.3$ & $21.7 \pm 11.7$ & $2.3 \pm 8.8$ & $29.7 \pm 11.6$ \\
\hline No. of position changes & $8.6 \pm 3.4$ & $7.1 \pm 1.9^{*}$ & $7.1 \pm 2.8^{*}$ & $16.7 \pm 9.0^{*}$ \\
\hline No. of forward movements & $3.3 \pm 1.3$ & $3.3 \pm 0.7^{*}$ & $4.8 \pm 1.8^{*}$ & $7.0 \pm 5.2$ \\
\hline No. of sideward jumps & $5.2 \pm 3.9$ & $3.0 \pm 1.3 *$ & $5.4 \pm 2.6$ & $9.8 \pm 2.9^{*}$ \\
\hline
\end{tabular}

$*_{p}<0.05$ vs control values

and $150(n=8) \mathrm{mg} / \mathrm{kg}$ modafinil. Only after $225 \mathrm{mg} / \mathrm{kg}$ modafinil did two of the six animals show decreased performance on the task (see Fig. 2).

\section{Startle response}

The startle response was not affected after any of the doses of modafinil (see Fig. 3).

\section{Human threat test}

Modafinil affected the body postures $[F(1,29)=29.2$, $p<0.001]$ (see Table 2). More specifically, the body postures were lowered after 50,150 , and $225 \mathrm{mg} / \mathrm{kg}$ modafinil $(p<0.05)$ and with a trend after $100 \mathrm{mg} / \mathrm{kg}$ $(p=0.053)$. A statistical increase was seen in the effects of modafinil on the 'time spent in front of the cage' $[F(1,29)$ $=4.1, p=0.052]$. This was due to an increase in time spent in front after 100 and $225 \mathrm{mg} / \mathrm{kg}(p=0.065$ and $p=0.051)$.

Modafinil increased the 'position changes in the cage' $[F(1,29)=16.5, p<0.001]$, the related 'movements forward' $[F(1,29)=16.5, p<0.001]$ and the 'jumps from side to side' $[F(1,29)=22.3, p<0.001]$. More detailed, the

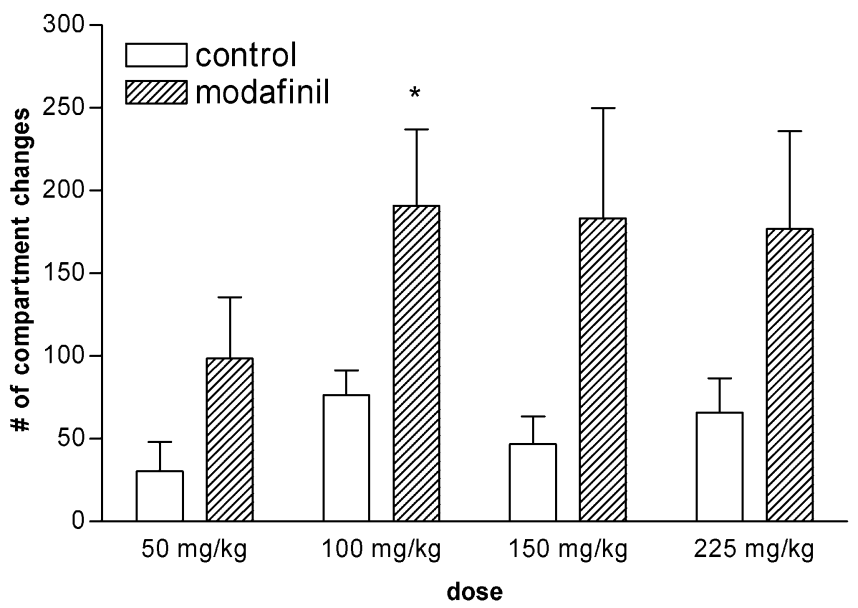

Fig. 1 Locomotor and exploratory activity assessed in the Bungalow test. Bars show mean $( \pm$ SEM) number of compartment changes of control values (before administration) and after $50(n=5)$, $100(n=9), 150(n=8)$, and $225(n=6) \mathrm{mg} / \mathrm{kg}$ of modafinil. $*<<0.05$ modafinil dose vs control values

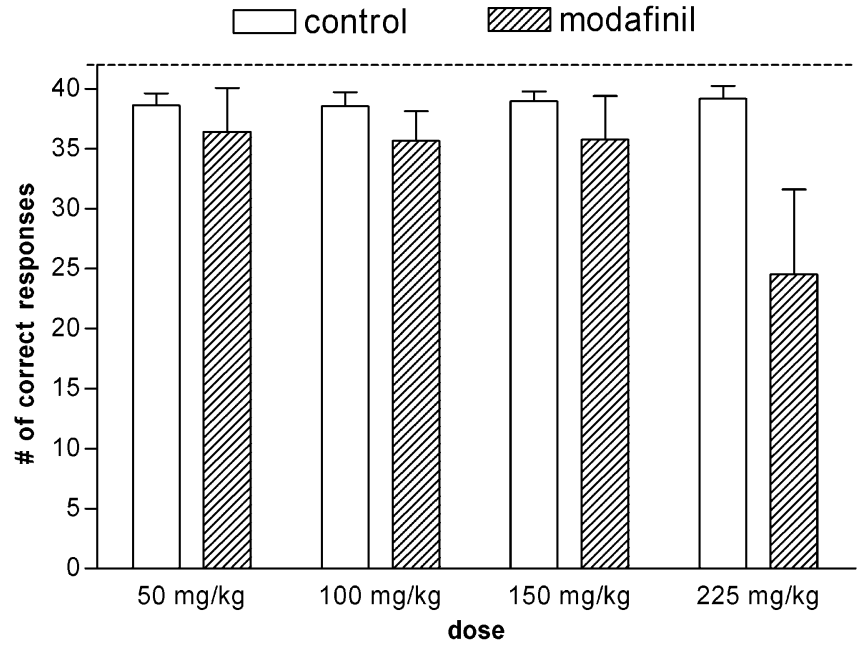

Fig. 2 Hand-eye coordination task. Bars show mean ( \pm SEM) number of correct responses of control values (before administration) and after $50(n=5), 100(n=9), 150(n=8)$, and $225(n=6) \mathrm{mg} / \mathrm{kg}$ of modafinil. Dotted line indicated maximum number of responses

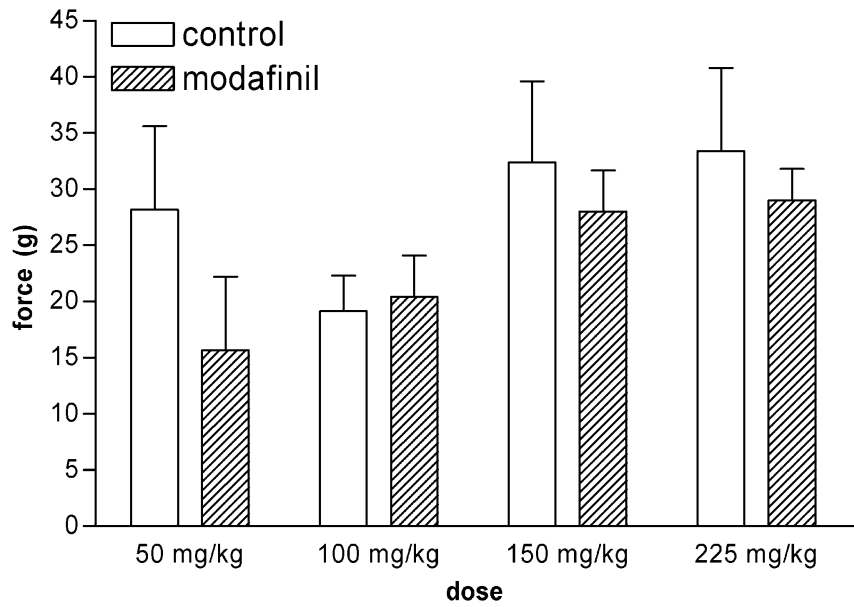

Fig. 3 Startle response. Bars show mean $( \pm$ SEM) of the amplitude of control values (before administration) and after $50(n=5), 100$ $(n=9), 150(n=8)$, and $225(n=5) \mathrm{mg} / \mathrm{kg}$ of modafinil

'position changes in the cage' increased after 100, 150, and $225 \mathrm{mg} / \mathrm{kg}(p<0.05)$ with a trend after $50 \mathrm{mg} / \mathrm{kg}$ $(p=0.053)$. The 'movements forward' increased after 100 and $150 \mathrm{mg} / \mathrm{kg}$ with a trend after $50 \mathrm{mg} / \mathrm{kg}(p=0.055)$. 
The 'jumps from side to side' increased after 100 and $225 \mathrm{mg} / \mathrm{kg}(p<0.05)$.

\section{Discussion}

In view of the increasing applications of modafinil in various therapeutic areas, including Parkinson's disease and sleep disorders, we assessed putative positive and aversive effects of modafinil in marmoset monkeys using observational methods and various behavioral test systems. Modafinil was tested in doses of 50,100, 150, and $225 \mathrm{mg} /$ $\mathrm{kg}$ in a time interval of 2 and $3 \mathrm{~h}$ after administration.

Increased activity was measured in the Bungalow test and during the human threat test on the parameters 'position changes', 'movements forward', and 'sideward jumps'. This increased activity was reported earlier in other species (Jenner et al. 2000; Simon et al. 1995; Ward et al. 2004). However, the increase in activity is not reported in humans, except related side effects, such as nervousness and insomnia (Robertson and Hellriegel 2003).

Other psychostimulants, such as caffeine and amphetamine, also increase locomotor activity (Eden et al. 1991; Fredholm et al. 1999). These compounds affect dopaminergic (DA) and noradrenergic systems, which are mainly involved in the control of locomotor activity (Anden et al. 1973). Modafinil does not modulate the DA system, as modafinil lacks pronounced effects on motor function areas (Engber et al. 1998; Lin et al. 1996). Indeed, the dopamine $\mathrm{D}_{2}$ receptor antagonists haloperidol and sulpiride did not prevent the modafinil-induced locomotor activity (Duteil et al. 1990). However, modafinil can increase DA transmission by binding weakly to the dopamine transporter (Mignot et al. 1994; Wisor et al. 2001) and the modafinil-induced increased c-fos in certain brain areas like striatum and amygdala seems moderated by substantial dopaminergic afferents (Scammell et al. 2000). Modulation of the NA system by modafinil seems more likely. Modafinil-induced locomotor activity was prevented by the $\alpha_{1}$-adrenoceptor antagonists, prazosin, and phenoxybenzamine (Duteil et al. 1990). Catecholamine depletion by reserpine also prevented modafinil-induced locomotor activity, but inhibition of tyrosine hydroxylase by AMPT ( $\alpha$-Methyl- $p$-tyrosine) had no effect. This indicates an indirect effect of endogenous NA stores stimulating the $\alpha_{1}$ adrenoreceptors (Duteil et al. 1990). Besides the effects on the NA system, modafinil reduces GABA release from striatal and pallidal areas of the basal ganglia without affecting glutamate release (Ferraro et al. 1998). It is quite probable that locomotor activity can be increased as a result of reduction of GABA release from the globus pallidus to the thalamus, where the increased glutamate levels result in excitatory output from the basal ganglia.

The increased locomotor activity was not accompanied by stereotypic behavior or other observable side effects, except at the highest doses. Hand-eye coordination was not changed after any dose of modafinil, although an overall effect was found. The setup of the hand-eye coordination task used could not reveal improvement of hand-eye coordination because the maximum number of correct responses had already been reached during training of the task. In healthy volunteers, modafinil did not affect the reaction time. On the other hand, the response latency was lower resulting, in reduced impulsive response (Turner et al. 2003). The lack of stereotypic behavior and minimal effects on hand-eye coordination, as tested in this study, seem to support the idea that modafinil does not exert its effects via the dopaminergic system.

Two parameters of the human threat test, the 'number of body postures' and 'time spent in front', are most sensitive to anxiolytic effects of drugs (Carey et al. 1992). This was also validated in the marmoset colony of our institute with the anxiolytic agent diazepam $(0.25 \mathrm{mg} / \mathrm{kg}$ i.m. $)$. Diazepam lowered the number of characteristic body postures and increased the time spent in the front of the cage (Van Vliet et al. 2005). In this study, modafinil reduced the 'number of body postures', and a trend for an overall increased 'time spent in front' after 100 and $225 \mathrm{mg} / \mathrm{kg}$ modafinil was observed. This can be due to increased activity, which is responsible for a reduced total time spent on a specific position. However, despite this, the ratio of place preference (front vs back of the cage) increased with 43 $\pm 5 \%$ after 100 and $225 \mathrm{mg} / \mathrm{kg}$ modafinil. The shift in place preference indicates that more time is spent in an aversive place after modafinil. Therefore, it can be concluded that the anxiolytic-like effects of modafinil are independent of the stimulative properties of modafinil.

Anxiolytic-like effects of modafinil have not been reported earlier. Simon et al. (1994) found no effects on anxiety in mice, but their tests were primarily designed to measure anxiogenic effects. Although anxiogenic effects have been mentioned as reported side effects in human studies (Robertson and Hellriegel 2003), the review does not mention what this conclusion of anxiogenic effects was based on, and the reference mentioned was only about narcolepsy patients.

As the body postures were reduced after modafinil, it was expected that effect on the 'time spent in front' would be clearer. Whereas, the latter parameter is very sensitive to anxiolytic effects and is the most frequently affected behavior in other studies (Barros and Tomaz 2002). One reason may be that no selection on animals with anxious behavior was carried out beforehand. Prior screening of the animals is fairly common in applications of the human threat test to reduce the inter-individual variability (Costall et al. 1988). The omission of pre-selection resulted in a higher baseline level $(24 \pm 5 \%)$ of the 'time spent in front'. Therefore, our expectation is that putative anxiolytic effects of modafinil would be more distinct after preselection and the animals less habituated to their environment and observer.

Anxiety can be reduced by benzodiazepines, like diazepam, which act on $\mathrm{GABA}_{\mathrm{A}}$-receptors (Nemeroff 2003). The anxiolytic-like effects of modafinil cannot be explained by a direct effect on $\mathrm{GABA}_{\mathrm{A}}$-receptor systems, although modafinil reduces GABA levels in hypothalamus and cerebral cortex outflow (Ferraro et al. 1999; Tanganelli et al. 1995). A potential advantage of modafinil over 
benzodiazepines in the treatment of anxiety is the lack of sedation, often seen after benzodiazepines.

In conclusion, modafinil increases locomotor activity in marmosets, probably the human counterpart of increases in nervousness and agitation. Also, modafinil shows minimal aversive effects, even at higher doses. Therefore, the effects of modafinil found in the marmoset monkey support the advantageous characteristics of this compound over other psychostimulants. The potential anxiolytic-like effects of modafinil in marmosets point to further examination of this new characteristic and may create new possibilities for the therapeutic use of modafinil.

\section{References}

Adler CH, Caviness JN, Hentz JG, Lind M, Tiede J (2003) Randomized trial of modafinil for treating subjective daytime sleepiness in patients with Parkinson's disease. Mov Disord 18:287-293

Anden NE, Strombom U, Svensson TH (1973) Dopamine and noradrenaline receptor stimulation: reversal of reserpine-induced suppression of motor activity. Psychopharmacologia 29:289-298

Barros M, Tomaz C (2002) Non-human primate models for investigating fear and anxiety. Neurosci Biobehav Rev 26:187-201

Bastuji H, Jouvet M (1988) Successful treatment of idiopathic hypersomnia and narcolepsy with modafinil. Prog Neuropsychopharmacol Biol Psychiatry 12:695-700

Beasley CM, Dellva MA, Tamura RN, Morgenstern H, Glazer WM, Ferguson K, Tollefson GD (1999) Randomised double-blind comparison of the incidence of tardive dyskinesia in patients with schizophrenia during long-term treatment with olanzapine or haloperidol. Br J Psychiatry 174:23-30

Carey GJ, Costall B, Domeney AM, Jones DN, Naylor RJ (1992) Behavioural effects of anxiogenic agents in the common marmoset. Pharmacol Biochem Behav 42:143-153

Costall B, Domeney AM, Gerrard PA, Kelly ME, Naylor RJ (1988) Zacopride: anxiolytic profile in rodent and primate models of anxiety. J Pharm Pharmacol 40:302-305

Di Monte DA, McCormack A, Petzinger G, Janson AM, Quik M, Langston WJ (2000) Relationship among nigrostriatal denervation, parkinsonism, and dyskinesias in the MPTP primate model. Mov Disord 15:459-466

Duteil J, Rambert FA, Pessonnier J, Hermant JF, Gombert R, Assous E (1990) Central alpha 1-adrenergic stimulation in relation to the behaviour stimulating effect of modafinil; studies with experimental animals. Eur J Pharmacol 180:49-58

Eden RJ, Costall B, Domeney AM, Gerrard PA, Harvey CA, Kelly ME, Naylor RJ, Owen DA, Wright A (1991) Preclinical pharmacology of ropinirole (SK\&F 101468-A) a novel dopamine D2 agonist. Pharmacol Biochem Behav 38:147-154

Engber TM, Dennis SA, Jones BE, Miller MS, Contreras PC (1998) Brain regional substrates for the actions of the novel wakepromoting agent modafinil in the rat: comparison with amphetamine. Neuroscience 87:905-911

Ferraro L, Tanganelli S, O'Connor WT, Antonelli T, Rambert F, Fuxe K (1996) The vigilance promoting drug modafinil decreases GABA release in the medial preoptic area and in the posterior hypothalamus of the awake rat: possible involvement of the serotonergic 5-HT3 receptor. Neurosci Lett 220:5-8

Ferraro L, Antonelli T, O'Connor WT, Tanganelli S, Rambert FA, Fuxe K (1998) The effects of modafinil on striatal, pallidal and nigral GABA and glutamate release in the conscious rat: evidence for a preferential inhibition of striato-pallidal GABA transmission. Neurosci Lett 253:135-138
Ferraro L, Antonelli T, Tanganelli S, O'Connor WT, Perez de la Mora M, Mendez-Franco J, Rambert FA, Fuxe K (1999) The vigilance promoting drug modafinil increases extracellular glutamate levels in the medial preoptic area and the posterior hypothalamus of the conscious rat: prevention by local GABAA receptor blockade. Neuropsychopharmacology 20:346-356

Fredholm BB, Battig K, Holmen J, Nehlig A, Zvartau EE (1999) Actions of caffeine in the brain with special reference to factors that contribute to its widespread use. Pharmacol Rev 51:83-133

Green PM, Stillman MJ (1998) Narcolepsy. Signs, symptoms, differential diagnosis, and management. Arch Fam Med 7: $472-478$

Guy W (1976) ECDEU assessment manual for psychopharmacology. U.S. Department of Health, Education and Welfare, Washington, District of Columbia, pp 534-537

Happe S (2003) Excessive daytime sleepiness and sleep disturbances in patients with neurological diseases: epidemiology and management. Drugs 63:2725-2737

Happe S, Pirker W, Sauter C, Klosch G, Zeitlhofer J (2001) Successful treatment of excessive daytime sleepiness in Parkinson's disease with modafinil. J Neurol 248:632-634

Jasinski DR, Kovacevic-Ristanovic R (2000) Evaluation of the abuse liability of modafinil and other drugs for excessive daytime sleepiness associated with narcolepsy. Clin Neuropharmacol 23:149-156

Jenner P, Zeng BY, Smith LA, Pearce RK, Tel B, Chancharme L, Moachon G (2000) Antiparkinsonian and neuroprotective effects of modafinil in the mptp-treated common marmoset. Exp Brain Res 133:178-188

Katzenschlager R, Manson AJ, Evans A, Watt H, Lees AJ (2004) Low dose quetiapine for drug induced dyskinesias in Parkinson's disease: a double blind cross over study. J Neurol Neurosurg Psychiatry 75:295-297

Koch M (1999) The neurobiology of startle. Prog Neurobiol 59:107-128

Larijani GE, Goldberg ME, Hojat M, Khaleghi B, Dunn JB, Marr AT (2004) Modafinil improves recovery after general anesthesia. Anesth Analg 98:976-981

Lin JS, Hou Y, Jouvet M (1996) Potential brain neuronal targets for amphetamine-, methylphenidate-, and modafinil-induced wakefulness, evidenced by c-fos immunocytochemistry in the cat Proc Natl Acad Sci U S A 93:14128-14133

Makela EH, Miller K, Cutlip WD (2003) Three case reports of modafinil use in treating sedation induced by antipsychotic medications. J Clin Psychiatry 64:485-486

Menza MA, Kaufman KR, Castellanos A (2000) Modafinil augmentation of antidepressant treatment in depression. J Clin Psychiatry 61:378-381

Mignot E, Nishino S, Guilleminault C, Dement WC (1994) Modafinil binds to the dopamine uptake carrier site with low affinity. Sleep 17:436-437

Nemeroff CB (2003) The role of GABA in the pathophysiology and treatment of anxiety disorders. Psychopharmacol Bull 37: $133-146$

Nieves AV, Lang AE (2002) Treatment of excessive daytime sleepiness in patients with Parkinson's disease with modafinil. Clin Neuropharmacol 25:111-114

Ninan PT, Hassman HA, Glass SJ, McManus FC (2004) Adjunctive modafinil at initiation of treatment with a selective serotonin reuptake inhibitor enhances the degree and onset of therapeutic effects in patients with major depressive disorder and fatigue. J Clin Psychiatry 65:414-420

Philippens IH, Melchers BP, Roeling TA, Bruijnzeel PL (2000) Behavioral test systems in marmoset monkeys. Behav Res Meth Instrum Comput 32:173-179

Philippens IH, Kersten CJ, Vanwersch RA, Strijkstra AM (2004) Sleep and sleep EEG data in marmoset monkeys. Sleep wake research in the Netherlands, vol 15. NSWO, Leiden, The Netherlands, pp 49-51 
Rammohan KW, Rosenberg JH, Lynn DJ, Blumenfeld AM, Pollak CP, Nagaraja HN (2002) Efficacy and safety of modafinil (Provigil) for the treatment of fatigue in multiple sclerosis: a two centre phase 2 study. J Neurol Neurosurg Psychiatry 72:179-183

Robertson P, Jr., Hellriegel ET (2003) Clinical pharmacokinetic profile of modafinil. Clin Pharmacokinet 42:123-137

Scammell TE, Estabrooke IV, McCarthy MT, Chemelli RM, Yanagisawa M, Miller MS, Saper CB (2000) Hypothalamic arousal regions are activated during modafinil-induced wakefulness. J Neurosci 20:8620-8628

Simon P, Panissaud C, Costentin J (1994) The stimulant effect of modafinil on wakefulness is not associated with an increase in anxiety in mice. A comparison with dexamphetamine. Psychopharmacology (Berl) 114:597-600

Simon P, Hemet C, Ramassamy C, Costentin J (1995) Nonamphetaminic mechanism of stimulant locomotor effect of modafinil in mice. Eur Neuropsychopharmacol 5:509-514

Stevenson MF, Poole TB (1976) An ethogram of the common marmoset (Calithrix jacchus jacchus): general behavioural repertoire. Anim Behav 24:428-451

Tanganelli S, Perez de la Mora M, Ferraro L, Mendez-Franco J, Beani L, Rambert FA, Fuxe K (1995) Modafinil and cortical gamma-aminobutyric acid outflow. Modulation by 5-hydroxytryptamine neurotoxins. Eur J Pharmacol 273:63-71

Taylor FB, Russo J (2000) Efficacy of modafinil compared to dextroamphetamine for the treatment of attention deficit hyperactivity disorder in adults. J Child Adolesc Psychopharmacol 10:311-320
Turner DC, Robbins TW, Clark L, Aron AR, Dowson J, Sahakian BJ (2003) Cognitive enhancing effects of modafinil in healthy volunteers. Psychopharmacology (Berl) 165:260-269

Turner DC, Clark L, Dowson J, Robbins TW, Sahakian BJ (2004) Modafinil improves cognition and response inhibition in adult attention-deficit/hyperactivity disorder. Biol Psychiatry 55:1031-1040

Van Vliet SA, Jongsma MJ, Vanwersch RA, Philippens IH (2005) Human threat test: a method to test anxiety related behavior in a marmoset monkey. In: Proceedings of Measuring Behavior 2005. L. P. Noldus et al. (eds) Wageningen: Noldus Information Technology: 472-473

Ward CP, Harsh JR, York KM, Stewart KL, McCoy JG (2004) Modafinil facilitates performance on a delayed nonmatching to position swim task in rats. Pharmacol Biochem Behav 78: 735-741

Webster L, Andrews M, Stoddard G (2003) Modafinil treatment of opioid-induced sedation. Pain Med 4:135-140

Wisor JP, Nishino S, Sora I, Uhl GH, Mignot E, Edgar DM (2001) Dopaminergic role in stimulant-induced wakefulness. J Neurosci 21:1787-1794

Woerner MG, Alvir JM, Saltz BL, Lieberman JA, Kane JM (1998) Prospective study of tardive dyskinesia in the elderly: rates and risk factors. Am J Psychiatry 155:1521-1528

Wolthuis OL, Groen B, Philippens IH (1994) A simple automated test to measure exploratory and motor activity of marmosets. Pharmacol Biochem Behav 47:879-881 